\title{
SUPRANACIONALIDADE COMO CONSTRUÇÃO DE VARIÁVEIS INTERVENIENTES 1
}

Supranationality as construction of intervenient variables

VIGNA, Edélcio ${ }^{2}$

Resumo: A proposta deste artigo é levantar a questão que a supranacionalidade não decorre apenas de uma variável, de tratados e acordos, que determinam áreas comuns de comércio, mas de outra série de variáveis e fatores, que podem ser concebidos como variantes teóricas e intervenientes. A supranacionalidade, neste artigo, é conceituada como uma relação entre identidade e territorialidade regional, que comporta elementos mais subjetivos do que objetivos, evitando, assim, uma leitura positivista, funcionalista ou estrutural-funcionalista. Os diversos fatores constitutivos da supranacionalidade, perpassam diversas dimensões e propõem uma nova forma de resistência contra a colonialidade gerada pela episteme neocolonialista euroamericana, que se impõe por meios mediáticos, culturais e estruturais.

Palavras-chaves: Supranacionalidade. Identidade. Território.

Abstract: The proposal of this article is to raise the question that supranationality does not come only from a variable, of treaties and agreements that determine common areas of commerce, but of another series of variables and factors that can be conceived as theoretical and intervening variants. Supranationality, in this article, is conceptualized as a relation between identity and regional territoriality, which involves elements that are more subjective than objective, thus avoiding a positivist, functionalist or structuralfunctionalist reading. The various constituent factors of supranationality span several dimensions and propose a new form of resistance against the coloniality generated by the Euro-American neocolonial episteme, which is imposed by mediatic, cultural and structural means.

Keywords: Supranationality. Identity. Territory.

\footnotetext{
${ }^{1}$ Recebido em: 14 Dez. 2017. Aprovado em: 31 Ago. 2018.

2 Doutor em Ciências Sociais, pelo Departamento de Estudos Latino-Americanos (ELA) é uma subunidade acadêmica da Universidade de Brasília (UnB), vinculada ao Instituto de Ciências Sociais (ICS). Mestre em Ciência Política, pelo Instituto de Política da Universidade de Brasília (IPOL/UnB). Licenciado em História, pela Faculdade de Filosofia, Ciências e Letras de Assis (UNESP). E-mail: edelcio.evo@gmail.com
} 


\section{Introdução}

O objetivo deste artigo é propor um debate em relação as variantes intervenientes que operam sobre o conceito de supranacionalidade 3 . A supranacionalidade, no contexto sul-americano, pode compreendida como uma relação entre identidade e territorialidade regional, que comporta mais elementos subjetivos do que objetivos. A síntese desses fatores, perpassa diversas dimensões e recruta diversos opositores, que se sentem ameaçados em seus domínios de poder, de territorialidade, pois liquefaz o sentimento piegas de patriotismo e nacionalismo, que tem fertilizado o terreno totalitário. Espera-se que no decorrer da narrativa essas enunciações possam ir se revelando e tomando o proscênio do artigo.

A questão da supranacionalidade relaciona-se, neste caso, com a questão da identidade e da territorialidade sul-americana. Pressupõe-se que se o discurso supranacional não estiver em sintonia com os interesses objetivos e subjetivos das sociedades, considerando suas experiências históricas e culturais, herdadas das lutas de seus antepassados, o termo supranacionalidade será apenas um vocábulo vazio de significado crítico ou terá apenas uma validade analítica estrutural.

Contribui para a definir o que seria uma proposta de construir uma identidade sulamericana, o projeto da Pluriversidade Amawtay Wasi ${ }^{4}$, que delineia uma supranacionalidade e estabelece uma nova epistemologia transformadora e contrahegemônica, entendida como um processo decolonial ao recolocar os povos no mesmo patamar continental. As populações europeias, por outro lado, não necessitaram descolonizar-se, pois foram os colonizadores.

A proposta [da Universidade Intercultural Amawtay Wasi] se orienta até a geração de um espaço de carácter intercultural alternativo para a coconstrução teórica, reflexiva, prática e complexa que facilite a compreensão do entorno global, nacional e local, articulando as diversas racionalidades e cosmovisões presentes nas diferentes culturas. Se trata

\footnotetext{
3 “Ocorrem, simplesmente porque em nossa realidade aquelas duas (causa-efeito) não se encontram isoladas, participam no devir do universo conjuntamente com muitíssimas outras variáveis presentes em seu entorno" (Pérez, J.A; 2007, p.171. Tradução livre).

${ }^{4}$ Projeto da Universidade Intercultural das Nacionalidades e Povos Indígenas «Amawtay Wasi» (Casa da Sabedoria), Confederação de Nacionalidades Indígenas do Equador (CONAIE) e do Instituto Científico de Culturas Indígenas (ICCI). http://www.amawtaywasi.org/
} 
de criar espaços de diálogo, reflexão, debate e co-construção, que permitam uma nova condição social do saber, do saber fazer e do saber ser, sem que se repliquem as relaciones de poder assimétricas que tem primado até hoje (CONAIE-ICCI, 2002, p.4)

Essa proposta acompanha a tendência de demarcar uma nova forma de resistência contra a colonialidade gerada pelo eurocentrismo e pela episteme neocolonialista estadunidense, que se impõe por meios mediáticos e culturais. Neste sentido, a supranacionalidade regional sul-americana avança junto com o processo de decolonização na medida que objetiva um amalgama de territórios, culturas e interesses sociais, que possa favorecer a ampla maioria das populações empobrecidas ao serem incorporadas regionalmente. O sociólogo peruano Aníbal Quijano concebe a decolonização como uma liberação da amarras do europeísmo e do pensamento único advindo de países centrais e hegemônicos.

A liberação das relações interculturais da prisão da colonialidade implica
uma liberdade de todas as pessoas, para escolher individualmente ou
coletivamente em tais relações; uma opção entre as diversas orientações
culturais. E sobretudo, a liberdade para produzir, criticar e mudar e
intercambiar cultura e sociedade. É parte, finalmente, do processo de
libertação social de todo o poder organizado como desigualdade, como
discriminação, como exploração e como dominação (Quijano, 1992,
p.447).

Na perspectiva de Quijano, a supranacionalidade se apresenta como um novo conceito que determina um novo território, que estabelece instituições novas ou distintas das que existem e que se autodenominam, em seus tratados constitutivos, como supranacionais, sejam organismos internacionais, regionais ou agências financeiras multilaterais. Conceitualmente o "território pode ser formado de lugares contíguos e de lugares em rede: são os mesmos lugares que formam redes e que formam o espaço banal. São os mesmos lugares, os mesmos pontos, mas contendo simultaneamente funcionalidades diferentes, quiçá divergentes ou opostas" (Santos, 2005).

Esta forma de identidade regional, em processo de construção, deve organizar suas instituições e foros, que sejam reconhecidos e legitimados pelos povos abrangidos por identidade comum. A supranacionalidade se refere às nações, e não aos Estados e suas instituições que podem ser ordenadoras de espaços mercadológicos (MERCOSUL e CAN), normatizadoras de regimes políticos (UNASUL) ou financiadoras de desenvolvimento (Banco do Sul, BNDES, além do Banco Interamericano de Desenvolvimento - BID, a 
Cooperação Andina de Fomento - CAF, e o Fundo Financeiro para o Desenvolvimento da Bacia do Prata - FONPLATA), entre outras. A subscrição de acordos e tratados regionais para criação e fusão de áreas de livre comércio, tais como a proposta da união do MERCOSUL com a CAN, fortalecendo a UNASUL e instituições multilaterais como os parlamentos regionais (PARLASUL, PARLANDINO, PARLATINO e PARLAMENTO da UNASUL), não farão prevalecer uma supranacionalidade entre os povos, que foram excluídos das construções dos estados nacionais, durante os processos de independência colonial. Os edifícios que foram levantados arquitetonicamente pelos acordos dos executivos nacionais, sem qualquer audiência popular, serão ruídos pelo tempo e deles não sobrarão nenhum traço que os identificará com a alma sul-americana.

\section{Desenvolvimento}

Os povos sul-americanos só se identificarão enquanto sujeitos históricos coletivos e regionais, quando forem unos e diversos ao mesmo tempo. Quando suas particularidades históricas e culturais estiverem ajustadas com outras histórias e culturas nacionais, gerando uma síntese constante, na qual nenhuma narrativa prevalecerá sobre outra. A esse movimento contínuo e criativo o sociólogo grego Kyriakos Kontopoulos denominou de Lógicas Heterárquicas, que é um "sistema onde não há um controle centralizado e predomina uma ordem consensual. Diferente da anarquia que é a ausência de centralização e da hierarquia, que impera a ordem centralizada" (Kontopoulos, 1993, p.209). De acordo com Santiago Castro-Gómez e Ramón Grosfoguel,

Em uma Heterarquia, a integração dos elementos disfuncionais ao sistema jamais é completa, como na hierarquia, senão parcial, o qual significa que no capitalismo global não existe lógicas autónomas nem tampouco uma só lógica determinante que governa sobre todas as demais, senão que mais bem existem processos complexos, heterogéneos e múltiplos, com diferentes temporalidades, dentro de um só sistemamundo de larga duração. No momento em que os múltiplos dispositivos de poder são considerados como sistemas complexos vinculados em rede, a ideia de uma lógica "em última instancia" e do domínio autónomo de uns dispositivos sobre outros desaparece (Castro-Gómez y Grosfoguel, 2007, p.18). 
Pode-se dizer que a construção da supranacionalidade operar-se-á sob a lógica da heterarquia, pois não deverá haver prevalência de uma particularidade de um país sobre o outro, no que diz respeito ao desenvolvimento socioeconômico, tecnológico e políticocultural, mas sim uma interação onde as experiências herdadas ou contemporâneas possam ser compartilhadas visando o impulso conjunto da região. A supranacionalidade será sempre apropriada de forma desigual, mas essa assimetria não deverá impedir que a região alcance um equilíbrio relativo à medida que operação vai integrando os elementos disfuncionais, como sugerem Castro-Gómez y Grosfoguel.

Assim, os países deverão manter suas características particulares, decorrentes da sua história e da sua ancestralidade cultural, que marcam suas nacionalidades e, ao mesmo tempo, deverão avançar no sentido de uma supranacionalidade sul-americana comum. 0 supranacional não significa a supressão do nacional, mas harmoniza-o em relação às outras nacionalidades. Dessa forma, a supranacionalidade é um instituto imaterial que, recepcionado pelas populações sul-americanas, processa e compatibiliza as macrodivergências. Neste sentido, não há um hegemón regional ou global que imponha ou articule os diversos fatores em função de seus interesses. 0 que se busca estruturar, com a supranacionalidade, é a harmonia dos interesse nacionais sem secundar as necessidades dos demais participantes desse instituto. Norberto Bobbio projeta, em seu Dicionário de Política, o fim dos Estados-nações:

É previsível que a história dos Estados nacionais esteja chegando ao fim e que esteja para começar uma nova fase em que o mundo se organizará em grandes espaços políticos federativos. Porém, se o federalismo significa o fim das Nações [...], significa também o renascimento [...] das nacionalidades espontâneas que o Estado nacional reduz a meros instrumentos ideológicos a serviço do poder político, e a volta daqueles autênticos sentimentos gregários dos quais a ideologia nacional se fez única detentora e que foram por ela transformados em valores dependentes (Bobbio, 2000, p.799).

Se a era dos Estados-nações está se esgotando, a preocupação com a segurança regional é prioridade no Boletim do Comando dos estrategistas e das autoridades que se ocupam da defesa nacional. Durante a reunião do Conselho de Defesa Sul-Americano (CDS), que debatia a criação de um Sistema Sul-Americano de Monitoramento de Áreas Especiais, o chanceler Celso Amorim, então Ministro da Defesa, dirigia-se aos integrantes:

Nossa reflexão sobre o papel da América do Sul no Sistema Internacional deve estar fundamentada na identidade democrática e não conflitiva que 
distingue nossa região. Deve basear-se no debate e no diálogo franco e honesto, respeitoso da diversidade e promotor dos princípios que nos unem, como a solução pacífica de controvérsias, o respeito à soberania e a prevalência dos direitos humanos, para citar alguns (Amorim, 2013).

0 Chanceler Amorim, mesmo tratando de um tema difícil como o da defesa militar, ressaltava o aspecto civil do projeto, que possibilitava uma ação multilateral entre os membros da Unasul. Contudo, esse programa de defesa não é nenhum avanço rumo à supranacionalidade porque não incorpora, de fato, a percepção valorativa das sociedades civis sul-americanas sobre o projeto. Os Estados, herdeiros de um legado autoritário militar, ainda estão excluindo as sociedades civis de participarem dos debates sobre as questões de defesa regional, como se este tema não afetasse a vida cotidiana das populações.

A história latino-americana oferece inúmeros exemplos dos efeitos negativos produzidos pelos planos de combate as drogas ou ao terrorismo desenhados pelo Pentágono, pelo Departamento de Defesa, pelo Escritório de Política Nacional de Controle de Drogas (ONDCP/EUA) ou pelas iniciativas econômico-militar, que foram introduzidas por meio de tratados de estabelecimento de bases militares em países sul-americanos, que veem acoplados aos acordos de livre comércio. A socióloga e economista Ana Esther Ceceña, afirma que a "iniciativa, flexível e versátil para adaptar-se aos cenários de mudanças sem perder a rota estratégica, marca a área latino-americana e caribenha estabelecendo uma amplia rede de bases militares e bases de operação antinarcóticos" (Ceceña 2014, p.130). De acordo com Noam Chomsky a cada ano:

[...] cerca de 300.000 novos refugiados são expulsos de seus pueblos, com um total de 3.000 mortos e inumeráveis massacres horríveis. A grande maioria de atrocidades é atribuída às forças paramilitares. Estas estão vinculadas aos militares, assim como documentou Human Rights Watch, em fevereiro de 2000, e um informe da ONU, o qual reportou que as forças de segurança colombiana que se fortaleceram imensamente com o Plano Colômbia mantém uma íntima relação com esquadrões da morte, organizam forças paramilitares, ou participam diretamente em seus massacres, ou por omissão tem possibilitado indubitavelmente que os grupos paramilitares alcancem seus objetivos exterminadores (Chomsky, 2000, p.11-12. Tradução livre). Prosseguiu

Diante da ofensiva conservadora sobre o território latino-americano articulada pelo Departamento de Estado Norte-Americano e pela CIA, que teve início com a omissão do Governo Obama no processo de golpe parlamentar que depôs a presidente Dilma 
Rousseff prosseguiu com a negociação para instalar duas base militares em território argentino e se consolidou com o apoio do governo de Donald Trump ao candidato da extrema direita Jair Bolsonaro à presidência do Brasil. 0 cientista político José Luis Ríos Vera declara que "para o imperialismo norte-americano, o Brasil constitui um anel geoestratégico e geopolítico de poder em seu interesse pela dominação e exploração da América Latina, bem como em suas guerras contra a China e a Rússia, que estão crescendo com força crescente na região" (Vera, 2019). Diversos centros de difusão de estudos vinculados aos setores militares-conservadores, como o caso do Caderno de Trabalho do Centro de Estudos Estratégicos, instrumento da direita chilena, fazem a seguinte análise da situação latino-americana:

No caso de América Latina e Caribe, muitas das mesquitas e centros islâmicos financiados diretamente pela Arábia Saudita ou bem influenciados ou gerenciados por movimentos ou grupos de clérigos fundamentalistas de outros países ou comunidades islâmicas, apresentam uma crescente influência salafista. (...). No casos como Panamá, Chile, Peru, Bolívia, Brasil e Argentina, Suriname e México, entre outros, existe ainda presencia de comunidades salafistas puristas, as que podem inda classificar-se como células dormentes (Wielandt, 2016, p.14).

É neste contexto de disputa geopolítica que se destaca a importância da participação da sociedade civil junto aos projetos políticos que alteram as condições de vida das populações locais e regionais. A corrida armamentista e os megaprojetos de mineração, de hidrelétricas, de vastas plantações de soja, de milho transgênicos e outras commodities de grande interesse no mercado internacional, afetam o meio ambiente regional em favor da alta das ações nas bolsas de valores de Chicago e Nova York. Essas iniciativas foram, mas não podem ser mais uma questão de soberania nacional ou questão específica de um país, mas uma questão dos Estados territorialmente estabelecidos e deve ser conduzida pela decisão coletiva das populações envolvidas e não somente a partir dos procedimentos formais e políticos das instituições supranacionais.

As instituições intergovernamentais de integração sofrem da morosidade burocrática e política, enquanto a sociedade civil regional, caso tivessem suficientemente unificadas suas demandas, poderiam ser as protagonistas do debate, da propagação e da disseminação de uma reflexão regional sobre a supranacionalidade, que deve ser adotada como um componente de um projeto maior que é a decolonização da região, face as 
amarras epistemológicas utilizadas pelos países europeus e pelos Estados Unidos, como grande hegemón global.

A construção da supranacionalidade orgânica, crítica e revolucionária, por meio da experiência e dos recursos existentes nas sociedades civis sul-americanas, é parte de um projeto proposto em rede, que rompe as fronteiras físicas e históricas dos países latinoamericanos. No caso do Brasil há a Rede Brasileira Pela Integração dos Povos (REBRIP), que está comprometida com a "construção de uma sociedade democrática pautada no desenvolvimento ético, justo e ambientalmente sustentável, atuando sempre em articulação com redes latino americanas e globais" (http://www.rebrip.org.br/). Porém, para implementar tal projeto supranacional é necessário um tipo de Estado participativo, organizado com fins de operar em função dos interesses nacionais. A proposição, manifestada por parte das sociedades civis, não deriva de uma visão funcionalista, da qual o Estado vai imperiosamente conduzir o processo de supranacionalidade, mas que não pode se omitir dos compromissos constitucionais.

Na década de 20 do século passado, os escritores poetas Oswald e Mário de Andrade, já ruminavam por toda América Latina os conceitos estéticos europeus - "uma civilização que ainda estamos deglutindo" - e que somente no final do século XX, os eurocentrista revelaram que "sem nós a Europa não teria sequer a sua pobre declaração dos direitos do homem" (Andrade, 1976). São estas heranças histórico-literárias, produtos de embates concretos e de desafios reais, que os atuais ativistas sul-americanos deverão se debruçar e aprofundar a pesquisa para mapear os métodos de como se libertar da psique da colonialidade, que impacta a vivência sul-americana como um estigma, mesmo quando estão no exilio, como escreveu o jornalista e poeta argentino Juan Gelman:

Quando certos europeus se dão conta da razão do exílio latino-americano,
mudam de expressão estranhamente, vacilam, empalidecem como se
lembrassem pavores da infância. Logo recobram a seriedade,
recompõem, reconhecem que a solidariedade é necessária e, sobretudo,
mutuamente solidária. Do sangue de muitos vão elaborar um ou dois
artigos, para alguma cátedra ou por um pequeno soldo. O qual carece de
importância. (Gelman, Poema XV, p.324).

Neste artigo, o que se busca destacar é que a supranacionalidade não se constrói nos tratados de livre comércio ou acordos internacionais, que estabelecem áreas de liberalização comercial entre as burocracias e os interesses estatais, mas na síntese 
cultural e histórica dos povos que se reconhecem nos seus poetas e cancioneiros. Não se contesta a importância dos pactos econômicos entre os países, o que se questiona é tomálos como suficientes para materializar a supranacionalidade. 0 que se reitera é que a narrativa da supranacionalidade independe das convenções e convênios bi ou multilaterais. 0 que se reafirma é que a identidade sul-americana, assim que esboçada como supranacional, construirá espaços físicos necessários para sua implementação e consolidação enquanto uma população geograficamente regionalizada. A supranacionalidade poderá, ou não, depender de tratados e de acordos, mas estes deverão ser distintos dos atuais termos de negociação, que se restringem à temática do comércio e da segurança nacional e regional.

Ao pesquisar a questão da supranacionalidade defrontamo-nos com inúmeros enfoques e variáveis, que tanto aclaram como obscurecem o termo. 0 conceito polidimensionalizado tem sido profusamente estudado sob a visão do direito internacional, que pode levar a uma leitura positivista ou estrutural-funcionalista, na medida que atribui caráter supranacional às instituições criadas a partir de acordos entre os Estados nacionais. São os regimentos internos e a construção de sedes que materializam a supranacionalidade. Neste diapasão, as sociedades civis não participaram dos debates, que levam à edificação dessas instituições regionais e, assim, os poderes constituídos ficam hospedados ou exilados em seus respectivos monumentos. Assim são as sedes da OEA, da UNASUL, do MERCOSUL, da CAN, do PARLANDINO, do PARLASUL, do PARLATINO e do PARLASUL, que restritos nas suas catedrais são caracterizados, pelos adeptos do método funcionalestrutural, como portadores originais da supranacionalidade.

0 termo supranacional foi concebido por Robert Schuman (2011), na Declaração de 9 de Maio de 1950, quando ao utilizar a expressão "federação da Europa" a delegação francesa reagiu negativamente e exigiu a substituição do termo 'federal por supranacional'. 0 documento oficial foi redigido da seguinte forma: "Cada Estado-Membro compromete-se a respeitar este carácter 'supranacional' e não procurar influenciar os membros da Alta Autoridade no desempenho das suas tarefas" (Comunidade Europeia do Carvão e do Aço-CECA, 1851, p. 23).

A proposta, que o artigo defende com tenacidade, é pensar a supranacionalidade como uma questão de identidade sul-americana e territorial em relação com o 
compromisso das populações nacionais em recuperar a identidade regional por meio do territorial. Ou seja, são as populações territorial e culturalmente identificadas que corporificarão o sentimento de supranacionalidade. Um estudo de maior fôlego deve considerar fatores temporais, participação das organizações sociais, estado das leis, formas de governo, prática política, entre outros, que podem ser empregados como variantes a serem consideradas no estudo da supranacionalidade. 0 alcance deste texto apenas esboça algumas variantes sem aprofundar o debate, pois o argumento, no caso, se restringe em advogar a subjetividade do conceito e sua possível consolidação por meio da legitimidade facultada pelas sociedades civis sul-americanas e não apenas pelos tratados e acordos internacionais.

A premissa que rege este artigo é que a supranacionalidade não é atributo do Estado ou do processo de globalização, mas uma questão a ser equacionada junto aos foros sociais, as aproximações e identificações comuns de interesses dos povos sulamericanos. Compreende-se, assim, o termo supranacional como uma identidade a ser construída pela sociedade sul-americana, que se sobrepõe às fronteiras geográficas e políticas da região, estabelecendo um novo território. Dessa forma, pode-se ter instituições supranacionais, mas não uma supranacionalidade ou uma identidade populacional comum de um território ampliado.

Em uma palavra: caminhamos, ao longo dos séculos, da antiga comunhão
individual dos lugares com o Universo à comunhão hoje global: a
interdependência universal dos lugares é a nova realidade do território.
Nesse longo caminho, o Estado-Nação foi um marco, um divisor de águas,
entronizando uma noção jurídico-política do território, derivada do
conhecimento e da conquista do mundo, desde o Estado Moderno e do
Século das Luzes à era da valorização dos recursos chamados naturais
(Santos, 2005, p.255).

Em vista das mudanças radicais que o processo de supranacionalidade poderá promover em todos os Estados nacionais é evidente que este encadeamento tem inúmeros oponentes. A supranacionalidade ao não ocultar os privilégios das elites dominantes, a exploração das grandes corporações nacionais e internacionais, ao não sustentar o status quo político-burocrático da nação, terá que se defrontar com as forças políticas e militares dos países centrais e hegemônicos. Esses opositores, inclusive os movimentos nacionalistas conservadores, sem dúvida, se agruparão independente de nacionalidades para frustrar o processo supranacional construído pelo novo paradigma. 
Neste sentido, mesmo os movimentos contra-hegemônicos, que sobrevivem no sistemamundo global, onde impera as desigualdades de riqueza e poder, serão profundamente afetados.

A supranacionalidade se revela como uma grande onda cívica, que manifestar-seá tal como um movimento social, territorial e regional, que envolverá todos os atores, seja em disputa ou em harmonia. O cientista político David Korten ao utilizar o termo “engajamento cívico" ressalta que a "democracia aprofunda o engajamento cívico igualitário, que é parte integrante da Comunidade da Terra, depende necessariamente de um senso maduro de confiança, responsabilidade e cuidado mútuos" (Korten, 2006, p.34). Nesta perspectiva, espera-se que os povos dos países sul-americanos envolvidos no processo de supranacionalidade reconheçam que existem princípios políticos que reservem aos indivíduos, independente de nacionalidade ou de quaisquer outras características, o "direito a voz nas decisões que moldam suas vidas, favorecendo o engajamento do cidadão inclusivo, a resolução cooperativa de problemas e a justiça restaurativa" (Korten, 2006, p.38).

Uma democracia mais madura busca garantir os direitos, afirmar as responsabilidades e apoiar o pleno desenvolvimento humano de todas as pessoas através do seu pleno e ativo engajamento na vida cívica para criar o que três célebres filósofos atenienses chamaram de "boa sociedade". [...]. A democracia e a maturidade política devem evoluir em conjunto através do envolvimento de todos nas responsabilidades da cidadania (Korten, 2006, p.146 e 152. Tradução livre).

Os movimentos sociais têm sido apontados por diversos autores como portadores de novas narrativas e construtores de alternativas, que independem do Estado e das estruturas político-partidárias. 0 sociólogo britânico Anthony Giddens confere a ação social coletiva o status de "modalidades de engajamento radical com importância difusa na vida social moderna, os movimentos sociais fornecem pautas para potenciais transformações futuras" (Giddens, 1991, p.140). No caso da supranacionalidade a questão fulcral não é a de classe nem étnica, mas de soberania popular no sentido de romper com os limites geográficos estabelecidos no início da era moderna pelas disputas coloniais, que moldaram a identidade e o imaginário sul-americano. No Mapa Mundi elaborado em 1532 - Novus Orbis Regionum -, pelo cosmógrafo Simon Grynaeus, o "continente americano aparece como una entidade geográfica separada, mas seus habitantes, representados no 
canto inferior esquerdo estão tipificados sob a imagem do canibal. [...]. São, portanto, seres infra-humanos que por natureza se acham fora da salvação" (Castro-Gómez, 2005, p.232).

Se, como nas famélicas sahelianas, os afetados não conseguem se adaptar à linguagem do mercado, da salvação (por marines norte-americanos ou as tropas internacionais), e da esperança cristã semi-secular, tanto pior para eles. Nestes casos, o olhar clínico, empresarial e militar parece unir forças para colocar em marcha operações supostamente benéficos e higiênicas para o bem da Humanidade. Restore Hope, Deserto Storm, Panamá e Granada são signos da chamada nova ordem mundial (Escobar, 2007, p.358).

Se os regimes operados pelos países centrais são lugares originais da violência e da diferença, como esperar que não irão se opor a qualquer movimento que busque estabelecer um sentimento de supranacionalidade territorial entre alguns países da América do Sul, que estão fora do mapa da modernidade? As américas Centro e Sul são constantes objetos de disputas e negociações nas tramas entre os Estados Unidos e os países europeus, incluídos a China e o Japão. As maiorias dos Estados dessas américas ainda são considerados, pelos países centrais, como reservatórios de pesquisas etnográficas, pois, segundo suas interpretações, essas nações são constituídas de grupos sociais múltiplos, fragmentados, polarizados, que estão transitando entre o atraso e um desenvolvimento carente de sustentabilidade. Poucos segmentos sociais dos países centrais, inclusive acadêmicos, até este momento não atentaram para o fato de que os movimentos culturais e políticos de resistência ao pensamento único alcançaram um estágio de inflexão irreversível e, assim, não podem retornar e aceitar passivamente a ideia da diferença de raça, nem mesmo do conceito de raça, que cientificamente legitimou o poder colonial. Aníbal Quijano e Santiago Castro-Gómez, afirmam que a “os colonizadores espanhóis entabularam com os colonizados uma relação de poder fundada na superioridade étnica e cognitiva dos primeiros sobre os segundos" (Castro-Gómez, 2005, p.62). Essa matriz de poder se sustentou pela força militar e por meio da transformação radical da forma como os dominados interpretavam o mundo a partir de suas crenças e tradições, impondo-lhes um novo horizonte cognitivo.

[...] os intentos de introduzir a linguajem da liberação àqueles que não a falam, como precondição para sua qualificação no que os modernos chamam de liberação, é uma farsa até da normatividade do conceito moderno de liberação. [...]. Para os mortais inferiores, constantemente em perigo de 'serem liberados' por uma minoria do mundo moderno, a resistência e a dissensão até as categorias impostas pela linguajem 
dominante é parte da luta pela sobrevivência (Escobar, 2007, p. 358 apud Nandy, 1989, p.269).

Neste espaço de resistência, a supranacionalidade sul-americana é um muro que os países centrais não podem deixar de considerar. Sua construção poderia detonar a guerra-fria do desenvolvimento regional, que não teria grande impacto no complexo militar, mas sim no complexo financeiro, pilar primeiro do sistema capitalista. Parafraseando Bruno Latour pode-se dizer que "o capitalismo ao aprofundar a exploração promoveu uma estranha dialética, que ressuscita o explorado e enterra o coveiro", após haver ensinado ao mundo como fazer uma guerra civil em grande escala (Latour, 1994, p.13). Carlos Gardin, doutor em Comunicação e Semiótica, escreve que Oswaldo de Andrade poderia ter relatado o processo de supranacionalidade da seguinte maneira: "Agora, os soterrados através da análise, voltam à luz, e, através da ação chegam às barricadas. (...). As catacumbas líricas ou se esgotaram ou desembocaram nas catacumbas políticas" (Gardin, 1995, p.35). Bizarra é a modernidade que acena com a liberdade e reprime a ação libertária. Ao se referir aos modernos Bruno Latour escreve: “Que enorme vantagem poder inverter os princípios sem que haja mesmo uma aparência de contradição" (Latour, 1994, p.42).

Ao pensar a possibilidade de compor de forma orgânica uma supranacionalidade a partir de povos segmentados e instrumentalizados pela razão ilustrada, que os hierarquizaram desde o século XVI, é contrariar a força da taxonomia da colonialidade. Essa categoria taxonômica marcou o lugar de origem e fixo de cada "raça", que a colonialidade gestou "com a formação do sistema-mundo, que se converte em base epistêmica do poder colonial" (Castro-Gómez, 2005, p.62). Para quebrar essas cadeias epistemológicas, se esquivar das armadilhas da colonialidade, é necessário romper com o conceito de sistema-mundo e enfrentar os sistemas autoritários, que se impuseram no sentido de implementar uma das fases mais agudas do capitalismo monopolista e financeiro.

A supranacionalidade dos povos sul-americanos, além de contrariar as convicções nacionalistas obtusas, vem delimitar outro mapa territorial, outro sentimento de pertencimento, que necessita ser recepcionado por uma nova epistemologia que consiga transmutá-lo em uma cultura decolonial. Ao ser uma ação agregadora, a supranacionalidade, adequada a um novo momento histórico do continente, não poderá 
germinar sob sistemas totalitários. Porém, o território supranacional não escapa da força de atração dos países centrais, porque a "quase-independência" que a supranacionalidade atribui ao território não o liberta da órbita das megaempresas multilaterais, pois este é um espaço nacional da economia internacional e os sistemas de inserção ao mercado global são melhores utilizados pelas transnacionais do que pelas sociedades nacionais. No campo de força do sistema-mundo "só os atores hegemónicos se servem de todas as redes e utilizam todos os territórios" (Santos, 1994, p.26).

\section{Considerações Finais}

A proposta deste artigo é relacionar a questão da identidade nacional com a da territorialidade sul-americana, que se caracteriza como uma identidade supranacional, e destacar algumas variáveis que compõem o conceito de supranacionalidade. Essa expressão tão disputada do ponto de vista funcional-estruturalista positivista, desproveuse de uma síntese dialética, que abranja outras dimensões da realidade. Neste texto a supranacionalidade é entendida como um processo decolonial na medida que estabelece uma epistemologia transformadora e contra-hegemônica. Assim, o argumento indica que a supranacionalidade, a ser construída a partir dos interesses dos povos regionais, representado pelas organizações da sociedade civil e lideranças eleitas de forma democrática, pode demarcar uma fronteira de resistência contra a colonialidade ao abrir um campo de embate ao eurocentrismo e a episteme neocolonialista estadunidense.

As agências financeiras multilaterais, os organismos internacionais e regionais apesar de trazerem a marca da supranacionalidade em seus estatutos e tratados constitutivos, não alteram o caráter territorial circunscritos por suas atividades. Isso acontece porque a sua supranacionalidade não ultrapassa as paredes das sedes, não alcançam a legitimidade que deveria ser atribuída pela comunidade sul-americana. Os edifícios-sedes não redefinem um novo território a partir de um contrato social regional.

Outra dimensão que deve operar o conceito de supranacionalidade é o da não prevalência de um país sobre o outro. Esse princípio, que descarta a rígida hierarquia, conduz a uma confluência de experiências vivenciadas e herdadas a ser compartilhadas 
entre os Estados e os povos regionais. Esta é uma variante que contribui, de forma essencial, para a análise teórica sobre o futuro da democracia participativa e do desenvolvimento na região.

Não se pode conceituar a supranacionalidade sem pensar a participação social, como uma das variantes intervenientes, que podem ou não interagirem a partir dos compromissos constitucionais mais ou menos libertários de cada país. Por isso, é importante, senão fundamental, a busca por uma síntese que incorpore elementos culturais e históricos dos povos e conduza o território sul-americano a um destino comum. $\mathrm{O}$ exercício que este artigo propiciou coloca de forma categórica a importância de se considerar outras variáveis, além das funcionais-estruturalistas, para se pensar a cidadania sul-americana ampliada como um desdobramento do sentimento de supranacionalidade. A pergunta, que resiste a análise, é se basta uma demonstração hipotética para afirmar uma verdade tão ampla, pois a supranacionalidade trata-se de um conceito geral, ou se para o caso se requer muito mais pesquisas?

Neste artigo, o que se discute é que o conceito polidimensionalizado de supranacionalidade, além de fazer emergir a força de outras variantes, deverá levantar uma série de opositores, que sentir-se-ão incomodados ao perceber que seus privilégios de classe estarão ameaçados. A supranacionalidade deverá se manifestar como uma onda cívica popular envolvendo as contradições em vários aspectos, que irão irromper por meio dos atores em disputa. Nesta perspectiva, a questão que se elevará não é a de classe e nem étnica, mas de soberania popular. Um embate entre a colonialidade e o imaginário sul-americano, que caminha em território próprio, um espaço, caso concretizado, será o da resistência.

\section{Referências}

AMORIM, Celso. (2013). A construção da identidade sul-americana em matéria de defesa. Abertura do I Seminário Sul-Americano sobre Monitoramento de Áreas Especiais, Manaus, 15 de Agosto de. 
ANDRADE, Oswald de. (1976). O manifesto antropófago. In: TELES, Gilberto Mendonça. Vanguarda europeia e modernismo brasileiro: apresentação e crítica dos principais manifestos vanguardistas. 3aㅡ ed. Petrópolis: Vozes; Brasília: INL, 1976.

BOBBIO, Norberto; MATTEUCCI, Nicola e PASQUINO, Gianfranco. (2000). Dicionário de Política. Trad. Carmen C, Varriale et al.; coord. trad. João Ferreira. Editora Universidade

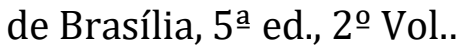

CASTRO-GÓMEZ, Santiago. (2005). La hybris del punto cero: ciencia, raza e ilustración en la Nueva Granada (1750-1816). 1a ed. -- Bogotá: Editorial Pontificia Universidad Javeriana.

CASTRO-GÓMEZ, Santiago y GROSFOGUEL, Ramón. (2007). Prólogo: Giro decolonial, teoría crítica y pensamiento heterárquico. In El giro decolonial: reflexiones para una diversidad epistémica más allá del capitalismo global. Biblioteca Universitaria, Serie Encuentros. Compiladores: Santiago Castro-Gómez y Ramón Grosfoguel. Ciencias Sociales y Humanidades. Bogotá.

CECEÑA, Ana E. (2014). La dominación de espectro completo sobre América. Revista de Estudos e Pesquisas sobre as Américas, Vol. 8, nr. 2.

CHOMSKY, Noam. Plan Colombia. (2000). INNOVAR, revista de ciencias administrativas y sociales. No. 16, Julio - Diciembre de 2000.

CONAIE-UINPI. "Amawtay wasi”. (2002). Casa de la sabiduría. Universidad intercultural de las nacionalidades y pueblos del Ecuador (UINPI-CONAIE). Propuesta de caminho sin camino. Quito

ESCOBAR, Arturo. (2007). La invención del Tercer Mundo: Construcción y deconstrucción del desarrollo. Serie colonialidad/modernidad/descolonialidad. Traducción de Diana Ochoa. 1ra. edición Fundación Editorial el perro y la rana, 2007. Caracas, Venezuela.

GARDIN, Carlos. (1995) O Rei nu ri do Rei nu: montagem em dois tempos. In 0 teatro antropofágico de Oswald de Andrade: da ação teatral ao teatro de ação. Annablume, 2 Edição. São Paulo, 1995

GELMAN, Juan. Poema XV. In Quintana, Jaime. Poesia de exilio de Juan Gelman. Universidad de Burgos. Biblioteca Virtual Universal, p. 324.

GUIMARÃES, Samuel P. (2008). Nação, nacionalismo, Estado. Estudos Avançados 22 (62), 2008.

FLÓREZ-FLÓREZ, Juliana. (2007). Lectura no eurocéntrica de los movimientos sociales latino-americanos: Las claves analíticas del proyecto modernidad/colonialidade. In El giro decolonial: reflexiones para una diversidad epistémica más allá del capitalismo global. Biblioteca Universitaria, Serie Encuentros. Compiladores: Santiago Castro-Gómez y Ramón Grosfoguel. Ciencias Sociales y Humanidades. Bogotá, 2007. 
GIDDENS, Anthony. (1991). As consequências da modernidade. Tradução de Raul Fiker. São Paulo: Editora UNESP.

KONTOPOULOS, Kyriakos M. (1993). The logics of social structure. Cambridge, New York. Cambridge University Press.

KORTEN, David. (2006). The Great Turning: From Empire to Earth Community. Editor Berrett-Koehler Publishers, 2006.

LATOUR, Bruno. Jamais fomos modernos: ensaio de antropologia simétrica. Tradução Carlos Irineu da Costa. Editora 34, Coleção Trans. Rio de Janeiro, 1994.

PÉREZ, J.A Las variables en el método científico. Rev Soc Quím Perú. 2007, 73, № 3 (171177).

SADER, Emir e BOFF, Leonardo. Bases militares dos EUA na América Latina apontam para risco de recolonização. RBA, 2016. http://www.redebrasilatual.com.br/mundo/2016/08/basesmilitares-dos-eua-na-america-latina-apontam-para-risco-de-recolonizacao-883.html (acessado em 01.06.2016)

SANTOS, Milton. 0 retorno do território. In Debates: Territorio y movimientos sociales. OSAL251 [año VI no 16 enero-abril 2005].

SANTOS, Milton - Técnica espaço tempo: Globalização e meio técnico científicoInformacional. São Paulo, maio de 1994.

VERA, José Luis Ríos. Brasil: La conquista geoestratégica del imperialismo. https://www.alainet.org/es/articulo/197824?utm_source=email\&utm_campaign=alaiamlatina (acessado em 01.02.2019)

VIGNA, Edélcio. O lado oculto da Supranacionalidade. Doutor em Ciências Sociais/Centro de Pesquisa e Pós-Graduação sobre as Américas-UnB. Texto a ser publicado. 2017.

WIELANDT, G.C. El terrorismo en latinoamérica y el caribe: realidades y desafíos. Caso del salafismo yihadista. Cuaderno de Trabajo del Centro de Estudios Estratégicos. Centro de Estudios Estratégicos de la Academia Nacional de Estudios Políticos y Estratégicos. Cuaderno de Trabajo №10-2016. 